\title{
Location, temporal tendency between 2003 e 2018 and relationship with deforestation
}

\author{
Rossano Marchetti Ramos ${ }^{1 *}$, Lawrence Nóbrega de Oliveiral, Yuri Roberta Yamaguchi de Paival, \\ Andre Luiz de Souza Azaneu ${ }^{1}$
}

\footnotetext{
${ }^{1}$ Instituto Brasileiro de Meio Ambiente e Recursos Naturais Renováveis (Ibama), Brasília, Brasil

*e-mail: rossano.ramos@ibama.gov.br
}

\begin{abstract}
In Amazon, the areas known as "Arc of deforestation" concentrate much of the Brazilian wildfires. The deforestation and forest degradation by fires are two of the processess that cause most of Brazilian greenhouse gas emissions. Although the estimates of emissions from deforestation are better known, those resulting from forest degradation are less accurate as it depends on monitoring the later trajectory of areas affected by fires. Understanding this temporal and spatial dynamics is a key issue for public policy actions and for better estimating greenhouse emissions.

The objective of this study was to evaluate the Amazon sites where the active fires concentrated between 2003 and 2018, the changes in these areas of fire concentration and the relationship of wildfires and deforestation. We used MODIS active fires dataset (afternoon data of AQUA satellite). We quantified the annual frequency of active fires in each cell of a squared grid ( side $=0.50$ ) to highlight areas of concentration and analyzed the tendency for increase or decrease in each cell using the Pearson Correlation. To identify land use and land cover we used data produced by MapBiomas (http://mapbiomas.org/).

The concentration of active fires was associated with economic (expansion of the agricultural frontier), climatic processes (new areas of the Amazon started to burn), and detection of active fires (suggesting that the detectin probability is not evenly distributed among the vegetation types). The temporal dynamics seems to be associated with economic processes, especially with the advance of the agricultural frontier and the consolidation of grain production in areas that have been deforested for a longer time. The Amazon agricultural frontier concentrates most of the active fires and there is a tendency of "migration" of the fires to the north, following the agricultural frontier. We found tendency of reduction fire counts in the consolidated deforestation areas across entire Deforestation Arc and a tendency of increase in more preserved forest cover areas near agricultural frontier. When evaluated on a detail scale, the active fires tend to be located in forested areas, close to deforested patches.
\end{abstract}

Keywords: forest fires, active fires, MODIS, Amazon 